\title{
The Electric Cars, a „Tsunami” of Temptations for the Lovers of Speed
}

\author{
Gabriela Opait ${ }^{\star}$
}

\begin{tabular}{l}
\hline \multicolumn{1}{c}{ A R T I C L E I N F O } \\
\hline Article history: \\
Accepted December 2020 \\
Available online December 2020 \\
\hline JEL Classification \\
C1, C12, C2 \\
Keywords: \\
Electric vehicles, Plug-in hybrid, \\
Hummer Ev, „offensive” power \\
\hline
\end{tabular}

\begin{abstract}
A B S T R A C T
The electric vehicles fascinate through them silent motions, stylish structures, speeds and fiability. The sales concerning the electric cars witnessed a spectacular rises in the previous years and these had in background a miscellaneous "palette" in offers from all the enterpresises which produce electric vehicles. The intent of this paper consists in to hold forth the algorithm of the previsions in the spheres of the worldwide sales regarding the electric vehicles and plug-in hybrid electric vehicles, tradings which will be on the road of success in the next years.
\end{abstract}

(C) 2020 EAI. All rights reserved.

\section{Introduction}

The seductions of the electric vehicles exert great concentrations in adrenalin for the lovers of speed, style and performance and for these characteristics, the new electric vehicles (EV) and plug-in hybrid models will conquer the hearts of the public and will win new segments of market at worldwide level. In this year, the Hummer Ev model impressed through „streamlined” shape, „offensive” power highlighted off-road and movements similar with the crabs when the model musted to achieve auto detours of the rocks. This original research was achieved with a view to display the augmentations in the near future regarding the worldwide values which have as target the numbers of battery electric vehicles in use, respectively the worldwide sales of plug-in hybrid electric vehicles and as well, the increments concerning the worldwide sales of plug-in light vehicles. In the first display of this research, we can see the technique applied for the achievement of the prognosises regarding the worldwide values of the battery electric vehicles in use. The second exposure introduces us in the „programming” of the manner through we can to prognose the worldwide values of plug-in hybrid electric vehicles in use. The third exposition presents us the method used for to achieve forecasts for the worldwide values of plug-in hybrid electric vehicles which will be selled. The fourth section acknowledges us the „itinerary” though we can to model prognosises which focuse the values for the worldwide sales of the plug-in light vehicles. For to build these purports we introduced the method of the prevision which had in background the „Least Squares Method”. The „stream” of the architecture named the „Least Squares Method” has as source a great mathematician, namely Johann Carl Friedrich Gauss.

2. The prognosis highlighted through the structure of the model concerning the values which have as target the worldwide numbers of battery electric vehicles in use

Table 1. The values which put in evidence the number of battery electric vehicles in use at worldwide level

\begin{tabular}{|c|c|}
\hline YEARS & $\begin{array}{c}\text { Th use at worldwide level } \\
\text { OF BATTERY ELECTRIC VEHICLES IN USE } \\
\left(10^{3}\right)\end{array}$ \\
\hline 2012 & $\mathbf{1 1 2 , 9 2}$ \\
\hline 2013 & $\mathbf{2 2 5 , 5 0}$ \\
\hline 2014 & $\mathbf{4 1 5 , 7 4}$ \\
\hline 2015 & $\mathbf{7 3 6 , 9 0}$ \\
\hline 2016 & $\mathbf{1 1 9 8 , 3 7}$ \\
\hline 2017 & $\mathbf{1 9 4 5 , 7 8}$ \\
\hline 2018 & $\mathbf{3 2 9 0 , 8 0}$ \\
\hline & The sourse: "Statistics Portal United States" \\
\hline
\end{tabular}


- if the "territorial profile" drawn by the values of the $\xi$ variable, namely the worldwide numbers of battery electric vehicles in use "twinkles" through the $\xi_{t_{i}}=a+b \cdot t_{i}$ "mould", $a$ and $b$ will be [4]:

$$
\begin{aligned}
& S=\sum_{i=1}^{n}\left(\xi_{i}-\xi_{t i}\right)^{2}=\min \Leftrightarrow S=\sum_{i=1}^{n}\left(\xi_{i}-a-b t_{i}\right)^{2}=\min \\
& \left\{\begin{array} { l } 
{ \frac { \partial S } { \partial a } = 0 } \\
{ \frac { \partial S } { \partial b } = 0 }
\end{array} \Rightarrow \left\{\begin{array} { l } 
{ 2 \sum _ { 1 = 1 } ^ { n } ( \xi _ { i } - a - b t _ { i } ) ( - 1 ) = 0 / ( - \frac { 1 } { 2 } ) } \\
{ 2 \sum _ { 1 = 1 } ^ { n } ( \xi _ { i } - a - b t _ { i } ) ( - t _ { i } ) = 0 / ( - \frac { 1 } { 2 } ) }
\end{array} \Rightarrow \left\{\begin{array}{l}
n a+b \sum_{i=1}^{n} t_{i}=\sum_{i=1}^{n} \xi_{i} \\
a \sum_{i=1}^{n} t_{i}+b \sum_{i=1}^{n} t_{i}^{2}=\sum_{i=1}^{n} \xi_{i} t_{i}
\end{array} \Rightarrow\right.\right.\right. \\
& a=\frac{\left|\begin{array}{ll}
\sum_{i=1}^{n} \xi_{i} & \sum_{i=1}^{n} t_{i} \\
\sum_{i=1}^{n} \xi_{i} t_{i} & \sum_{i=1}^{n} t_{i}{ }^{2}
\end{array}\right|}{\left|\begin{array}{cc}
n & \sum_{i=1}^{n} t_{i} \\
\sum_{i=1}^{n} t_{i} & \sum_{i=1}^{n} t_{i}{ }^{2}
\end{array}\right|}=\frac{\sum_{i=1}^{n} \xi_{i} \sum_{i=1}^{n} t_{i}{ }^{2}-\sum_{i=1}^{n} \xi_{i} t_{i} \sum_{i=1}^{n} t_{i}}{n \sum_{i=1}^{n} t_{i}{ }^{2}-\left(\sum_{i=1}^{n} t_{i}\right)^{2}} \quad b=\frac{\left|\begin{array}{cc}
n & \sum_{i=1}^{n} x_{i} \\
\sum_{i=1}^{n} t_{i} & \sum_{i=1}^{n} \xi_{i} t_{i}
\end{array}\right|}{\left|\begin{array}{cc}
n & \sum_{i=1}^{n} t_{i} \\
\sum_{i=1}^{n} t_{i} & \sum_{i=1}^{n} t_{i}{ }^{2}
\end{array}\right|}=\frac{n \sum_{i=1}^{n} \xi_{i} t_{i}-\sum_{i=1}^{n} t_{i} \sum_{i=1}^{n} \xi_{i}}{n \sum_{i=1}^{n} t_{i}{ }^{2}-\left(\sum_{i=1}^{n} t_{i}\right)^{2}}
\end{aligned}
$$

\begin{tabular}{|c|c|c|c|c|c|c|}
\hline \multirow{2}{*}{ YEARS } & \multirow{2}{*}{$\begin{array}{l}\text { THE WORLDWIDE } \\
\text { NUMBER } \\
\text { OF BATTERY } \\
\text { ELECTRIC VEHICLS } \\
\text { IN USE } \\
\text { (THOUSANDS } \\
\text { UNITS) } \\
\left(\xi_{i}\right)\end{array}$} & \multicolumn{5}{|c|}{ LINEAR TENDENCY } \\
\hline & & $t_{i}$ & $t_{i}^{2}$ & $t_{i} \xi_{i}$ & $\xi_{t_{i}}=a+b t_{i}$ & $\left|\xi_{i}-\xi_{t_{i}}\right|$ \\
\hline 2012 & 112,92 & -3 & 9 & $-338,76$ & $-341,6589283$ & 454,58 \\
\hline 2013 & 225,50 & -2 & 4 & $-451,00$ & 149,6564288 & 75,84 \\
\hline 2014 & 415,74 & -1 & 1 & $-415,74$ & 640,9717859 & 225,23 \\
\hline 2015 & 736,90 & 0 & 0 & 0 & 1132,287143 & 395,39 \\
\hline 2016 & 1198,37 & +1 & 1 & 1198,37 & 1623,602500 & 425,23 \\
\hline 2017 & 1945,78 & +2 & 4 & 3891,56 & 2114,917857 & 169,14 \\
\hline 2018 & 3290,80 & +3 & 9 & 9872,40 & 2606,233214 & 684,57 \\
\hline TOTAL & 7926,01 & & 28 & 13756,83 & 7926,01 & 2429,98 \\
\hline
\end{tabular}

Table 2. The „recipe of the composition” for the values of the $\xi$ variable, namely the worldwide values concerning the battery electric vehicles in use, if the "profile” has as hypothesis a linear tendency

$$
\begin{gathered}
a=\frac{7926,01 \cdot 28}{7 \cdot 28}=1132,287143 \\
b=\frac{7 \cdot 13756,83}{7 \cdot 28}=491,3153571 \\
v_{I}=\left[\frac{\sum_{i=-m}^{m}\left|\xi_{i}-\xi_{t_{i}}^{I}\right|}{n}: \frac{\sum_{i=-m}^{m} \xi_{i}}{n}\right] \cdot 100=\frac{\sum_{i=-m}^{m}\left|\xi_{i}-\xi_{t_{i}}^{I}\right|}{\sum_{i=-m}^{m} \xi_{i}} \cdot 100=\frac{2429,98}{7926,01} \cdot 100=30,66 \%
\end{gathered}
$$

- if the "territorial profile" drawn by the values of the $\xi$ variable, namely the worldwide numbers of battery electric vehicles in use "twinkles” through the $\xi_{t_{i}}=a+b \cdot t_{i}+c t_{i}^{2}$ "mould”, $a$ and $b$ will be [4]:

$$
S=\sum_{i=1}^{n}\left(\xi_{i}-x_{t i}\right)^{2}=\min \Leftrightarrow S=\sum_{i=1}^{n}\left(\xi_{i}-a-b t_{i}-c t_{i}^{2}\right)^{2}=\min
$$




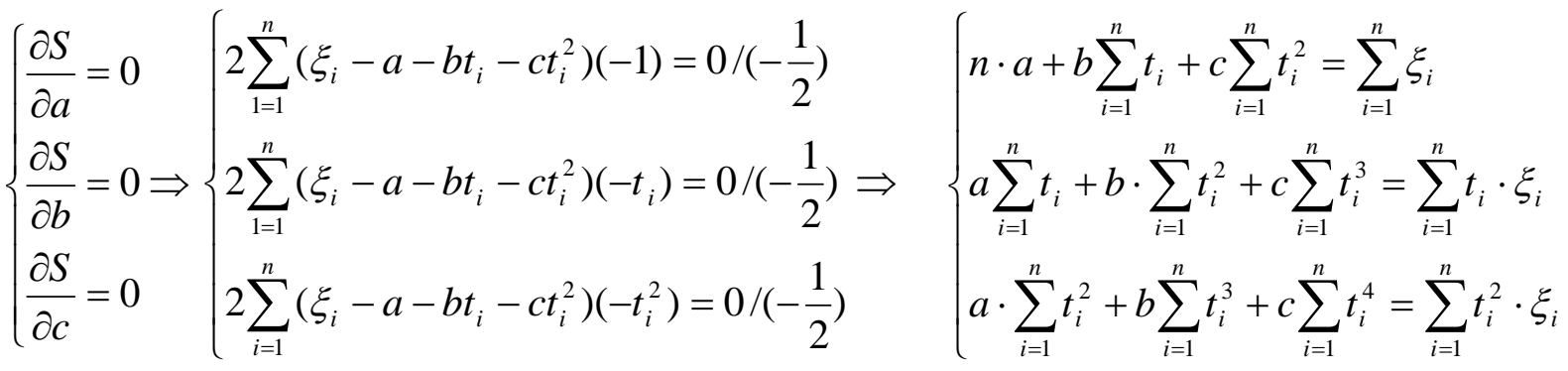

$$
\begin{aligned}
& a=\frac{\sum_{i=1}^{n} t_{i}^{4} \sum_{i=1}^{n} \xi_{i}-\sum_{i=1}^{n} t_{i}^{2} \sum_{i=1}^{n} t_{i}^{2} \cdot \xi_{i}}{n \sum_{i=1}^{n} t_{i}{ }^{4}-\left(\sum_{i=1}^{n} t_{i}^{2}\right)^{2}} ; \quad b=\frac{\sum_{i=1}^{n} \xi_{i} t_{i}}{\sum_{i=1}^{n} t_{i}^{2}} ; c=\frac{n \cdot \sum_{i=1}^{n} t_{i}^{2} \cdot \xi_{i}-\sum_{i=1}^{n} t_{i}^{2} \cdot \sum_{i=1}^{n} \xi_{i}}{n \sum_{i=1}^{n} t_{i}{ }^{4}-\left(\sum_{i=1}^{n} t_{i}^{2}\right)^{2}}
\end{aligned}
$$

Table 3. The „recipe of texture” for the values of the $\xi$ variable, namely the worldwide values concerning the battery electric vehicles in use, if the „profile” has as hypothesis a quadratic tendency

\begin{tabular}{|c|c|c|c|c|c|c|c|}
\hline \multirow{2}{*}{ YEARS } & \multirow{2}{*}{$\begin{array}{c}\text { THE WORLDWIDE } \\
\text { NUMBER } \\
\text { OF BATTERY } \\
\text { ELECTRIC } \\
\text { VEHICLES IN USE } \\
\text { (THOUSANDS } \\
\text { UNITS) } \\
\left(\xi_{i}\right)\end{array}$} & \multicolumn{6}{|c|}{ PARABOLIC TENDENCY } \\
\hline & & $t_{i}$ & $t_{i}^{2}$ & $t_{i}^{4}$ & $t_{i}^{2} \xi_{i}$ & $\xi_{t_{i}}=a+b t_{i}+c t_{i}^{2}$ & $\left|\xi_{i}-\xi_{t_{i}}\right|$ \\
\hline 2012 & 112,92 & -3 & 9 & 81 & 1016,28 & 207,6666664 & 94,75 \\
\hline 2013 & 225,50 & -2 & 4 & 16 & 902,00 & 149,6564285 & 75,84 \\
\hline 2014 & 415,74 & -1 & 1 & 1 & 415,74 & 311,3764286 & 104,36 \\
\hline 2015 & 736,90 & 0 & 0 & 0 & 0 & 692,8266667 & 44,07 \\
\hline 2016 & 1198,37 & +1 & 1 & 1 & 1198,37 & 1294,007143 & 95,64 \\
\hline 2017 & 1945,78 & +2 & 4 & 16 & 7783,12 & 2114,917857 & 169,14 \\
\hline 2018 & 3290,80 & +3 & 9 & 81 & 29617,20 & 3155,558809 & 135,24 \\
\hline TOTAL & 7926,01 & & 28 & 196 & 40932,71 & 7926,01 & 719,04 \\
\hline
\end{tabular}

$$
\begin{gathered}
a=\frac{196 \cdot 7926,01-28 \cdot 40932,71}{7 \cdot 196-28^{2}}=692,8266667 \\
b=\frac{7 \cdot 13756,83}{7 \cdot 28}=491,3153571 c=\frac{7 \cdot 40932,71-28 \cdot 7926,01}{7 \cdot 196-28^{2}}=109,865119 \\
v_{I I}=\left[\frac{\sum_{i=-m}^{m}\left|\xi_{i}-\xi_{t_{i}}^{I I}\right|}{n}: \frac{\sum_{i=-m}^{m} \xi_{i}}{n}\right] \cdot 100=\frac{\sum_{i=-m}^{m}\left|\xi_{i}-\xi_{t_{i}}^{I I}\right|}{\sum_{i=-m}^{m} \xi_{i}} \cdot 100=\frac{719,04}{7926,01} \cdot 100=9,07 \%
\end{gathered}
$$

- if the "territorial profile" drawn by the values of the $\xi$ variable, namely the worldwide numbers of battery electric vehicles in use "twinkles" through the $\xi_{t_{i}}=a b^{t_{i}}$ "mould”, $a$ and $b$ will be [4]:

$$
\begin{gathered}
S=\sum_{i=1}^{n}\left(\lg \xi_{i}-\lg \xi_{t_{i}}\right)^{2}=\min \Leftrightarrow S=\sum_{i=1}^{n}\left(\lg \xi_{i}-\lg a-t_{i} \lg b\right)^{2}=\min \\
\left\{\begin{array} { l } 
{ \frac { \partial S } { \partial \operatorname { l g } a } = 0 } \\
{ \frac { \partial S } { \partial \operatorname { l g } b } = 0 }
\end{array} \Rightarrow \left\{\begin{array} { l } 
{ 2 \sum _ { 1 = 1 } ^ { n } ( \operatorname { l g } \xi _ { i } - \operatorname { l g } a - t _ { i } \operatorname { l g } b ) ( - 1 ) = 0 / ( - \frac { 1 } { 2 } ) } \\
{ 2 \sum _ { 1 = 1 } ^ { n } ( \operatorname { l g } \xi _ { i } - \operatorname { l g } a - t _ { i } \operatorname { l g } b ) ( - t _ { i } ) = 0 / ( - \frac { 1 } { 2 } ) }
\end{array} \Rightarrow \left\{\begin{array}{l}
n \cdot \lg a+\lg b \cdot \sum_{i=1}^{n} t_{i}=\sum_{i=1}^{n} \lg \xi_{i} \\
\lg a \sum_{i=1}^{n} t_{i}+\lg b \cdot \sum_{i=1}^{n} t_{i}^{2}=\sum_{i=1}^{n} t_{i} \cdot \lg \xi_{i}
\end{array}\right.\right.\right.
\end{gathered}
$$




$$
\lg a=\frac{\left|\begin{array}{ll}
\sum_{i=1}^{n} \lg \xi_{i} & \sum_{i=1}^{n} t_{i} \\
\sum_{i=1}^{n} t_{i} \lg \xi_{i} & \sum_{i=1}^{n} t_{i}{ }^{2}
\end{array}\right|}{\left|\begin{array}{cc}
n & \sum_{i=1}^{n} t_{i} \\
\sum_{i=1}^{n} t_{i} & \sum_{i=1}^{n} t_{i}{ }^{2}
\end{array}\right|}=\frac{\sum_{i=1}^{n} \lg \xi_{i} \sum_{i=1}^{n} t_{i}{ }^{2}-\sum_{i=1}^{n} t_{i} \lg \xi_{i} \sum_{i=1}^{n} t_{i}}{n \sum_{i=1}^{n} t_{i}{ }^{2}-\left(\sum_{i=1}^{n} t_{i}\right)^{2}}
$$$$
\lg b=\frac{\left|\begin{array}{cc}
n & \sum_{i=1}^{n} \lg \xi_{i} \\
\sum_{i=1}^{n} t_{i} & \sum_{i=1}^{n} t_{i} \lg \xi_{i}
\end{array}\right|}{\left|\begin{array}{cc}
n & \sum_{i=1}^{n} t_{i} \\
\sum_{i=1}^{n} t_{i} & \sum_{i=1}^{n} t_{i}{ }^{2}
\end{array}\right|}=\frac{n \cdot \sum_{i=1}^{n} t_{i} \lg \xi_{i}-\sum_{i=1}^{n} \lg \xi_{i} \sum_{i=1}^{n} t_{i}}{n \sum_{i=1}^{n} t_{i}{ }^{2}-\left(\sum_{i=1}^{n} t_{i}\right)^{2}}
$$

Table 4. The „recipe of the mix" for the values of the $\xi$ variable, namely the worldwide values concerning the battery electric vehicles in use, if the „profile” has as hypothesis an exponential trend

\begin{tabular}{|c|c|c|c|c|c|c|}
\hline \multirow{2}{*}{ YEARS } & \begin{tabular}{c} 
THE WORLDWIDE \\
NUMBER \\
OF BATTERY \\
ELECTRIC \\
VEHICLES IN USE \\
(THOUSANDS \\
UNITS) \\
\cline { 3 - 7 }
\end{tabular} & $\lg \xi_{i}$ & $t_{i} \lg \xi_{i}$ & $\lg \xi_{t_{i}}=\lg a+t_{i} \lg b$ & $\xi_{t_{i}}=a b^{t_{i}}$ & $\left|\xi_{i}-\xi_{t_{i}}\right|$ \\
\cline { 3 - 7 } & & & & & & \\
\hline $\mathbf{2 0 1 2}$ & $\mathbf{1 1 2 , 9 2}$ & 2,052770869 & $-6,158312608$ & 2,101527491 & 126,3361073 & 13,42 \\
\hline $\mathbf{2 0 1 3}$ & $\mathbf{2 2 5 , 5 0}$ & 2,353146546 & $-4,706293092$ & 2,342786610 & 220,1844324 & 5,32 \\
\hline $\mathbf{2 0 1 4}$ & $\mathbf{4 1 5 , 7 4}$ & 2,618821812 & $-2,618821812$ & 2,584045729 & 383,7476500 & 31,99 \\
\hline $\mathbf{2 0 1 5}$ & $\mathbf{7 3 6 , 9 0}$ & 2,867408557 & 0 & 2,825304848 & 668,8132186 & 68,09 \\
\hline $\mathbf{2 0 1 6}$ & $\mathbf{1 1 9 8 , 3 7}$ & 3,078590928 & 3,078590928 & 3,066563967 & 1165,638724 & 32,73 \\
\hline $\mathbf{2 0 1 7}$ & $\mathbf{1 9 4 5 , 7 8}$ & 3,289093735 & 6,578187470 & 3,307823187 & 2031,529752 & 85,75 \\
\hline $\mathbf{2 0 1 8}$ & $\mathbf{3 2 9 0 , 8 0}$ & 3,517301489 & 10,55190447 & 3,549082205 & 3540,643535 & 249,84 \\
\hline TOTAL & $\mathbf{7 9 2 6 , 0 1}$ & 19,77713394 & 6,755255352 & & & 454,41 \\
\hline
\end{tabular}

$$
\begin{gathered}
\lg a=\frac{19,77713394 \cdot 28}{7 \cdot 28}=2,825304848 \\
\lg b=\frac{7 \cdot 6,755255352}{7 \cdot 28}=0,241259119 \\
v_{\text {exp }}=\left[\frac{\sum_{i=-m}^{m}\left|\xi_{i}-\xi_{t_{i}}^{\exp }\right|}{n}: \frac{\sum_{i=-m}^{m} \xi_{i}}{n}\right] \cdot 100=\frac{\sum_{i=-m}^{m}\left|\xi_{i}-\xi_{t_{i}}^{\exp }\right|}{\sum_{i=-m}^{m} \xi_{i}} \cdot 100=\frac{454,41}{7926,01} \cdot 100=5,73 \% \\
v_{\text {exp }}=5,73 \%<v_{I I}=9,07 \%<v_{I}=30,66 \%
\end{gathered}
$$

The look regarding the progress reflected by $\xi$ variable, namely the worldwide values concerning the battery electric vehicles, is moulded by the $\xi_{t_{i}}=a b^{t_{i}}$ exponential contour.

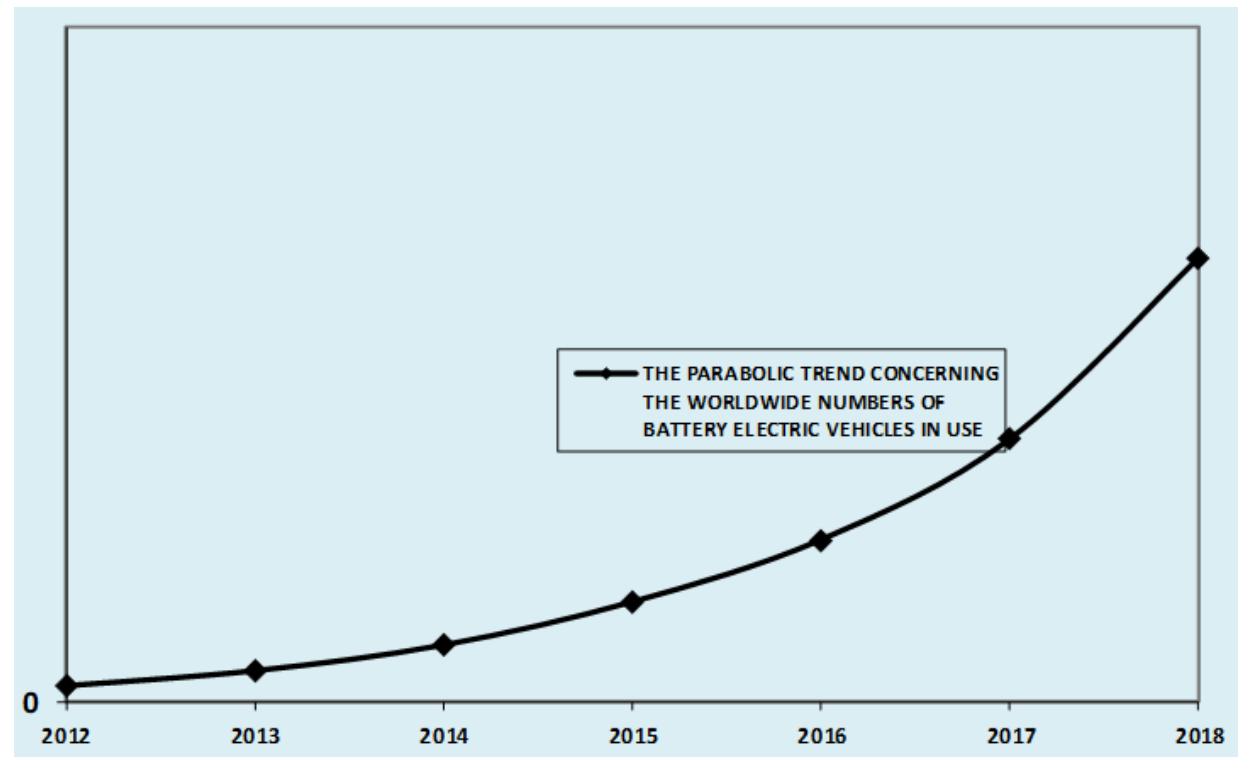

Graph 1. The quadratic countenance concerning the worldwide values 
of battery electric vehicles in use

$\xi_{2020}^{\text {WORLDWIDE_BATTERY_ELECTRIC_VEHICLES_IN_USE }}=668,8132186 \cdot 1,742846421^{5}=10754,75$ _thousands_units

$\xi_{2021}^{\text {WORLDWIDE_BATTERY_ELECTRIC_VEHICLES_IN_USE }}=668,8132186 \cdot 1,742846421^{6}=18743,88_{-}$_thousands_units

3. The forecasts exhibited through the texture of the model regarding the values which focuse the worldwide numbers of plug-in hybrid electric vehicles in use

Table 5. The values which put in evidence the number of plug-in hybrid electric vehicles in use at worldwide level

\begin{tabular}{|c|c|}
\hline YEARS & $\begin{array}{c}\text { THE WORLDWIDE NUMBER OF PLUG-IN HYBRID ELECTRIC VEHICLES IN USE } \\
\text { (millions units) }\end{array}$ \\
\hline 2016 & $\mathbf{0 , 8 1}$ \\
\hline 2017 & $\mathbf{1 , 2 0}$ \\
\hline 2018 & $\mathbf{1 , 8 2}$ \\
\hline \multicolumn{2}{|c|}{} \\
\hline
\end{tabular}

- if the "territorial profile" drawn by the values of the $\omega$ variable, namely the worldwide number of plug-in hybrid electric vehicles in use, „twinkles” through the $\omega_{t_{i}}=a+b \cdot t_{i}$ "mould”, $a$ and $b$ will be [4]:

Table 6. The „recipe of the composition” for the grouping of the values regarding the $\omega$ variable, namely the worldwide number of plug-in hybrid electric vehicles in use, if the „profile” has as hypothesis a linear tendency

\begin{tabular}{|c|c|c|c|c|c|c|}
\hline \multirow[b]{2}{*}{ YEARS } & \multirow{2}{*}{$\begin{array}{c}\text { THE WORLDWIDE } \\
\text { NUMBER OF PLUG- } \\
\text { IN HYBRID } \\
\text { ELECTRIC } \\
\text { VEHICLES IN USE } \\
\text { (MILLIONS UNITS) } \\
\left(\omega_{i}\right)\end{array}$} & \multicolumn{5}{|c|}{ LINEAR TENDENCY } \\
\hline & & $t_{i}$ & $t_{i}^{2}$ & $t_{i} \omega_{i}$ & $\omega_{t_{i}}=a+b t_{i}$ & $\omega_{i}-\omega_{t_{i}}$ \\
\hline 2016 & 0,81 & -1 & 1 & $-0,81$ & 0,7716666666 & 0,04 \\
\hline 2017 & 1,20 & 0 & 0 & 0 & 1,2766666667 & 0,08 \\
\hline 2018 & 1,82 & +1 & 1 & 1,82 & 1,781666667 & 0,04 \\
\hline TOTAL & 3,83 & & 2 & 1,01 & 3,83 & 0,16 \\
\hline
\end{tabular}

$$
\begin{gathered}
a=\frac{3,83 \cdot 2}{3 \cdot 2}=1,276666667 ; b=\frac{3 \cdot 1,01}{3 \cdot 2}=0,505 \\
v_{I}=\left[\frac{\sum_{i=-m}^{m}\left|\omega_{i}-\omega_{t_{i}}^{I}\right|}{n}: \frac{\sum_{i=-m}^{m} \omega_{i}}{n}\right] \cdot 100=\frac{\sum_{i=-m}^{m}\left|\omega_{i}-\omega_{t_{i}}^{I}\right|}{\sum_{i=-m}^{m} \omega_{i}} \cdot 100=\frac{0,16}{3,83} \cdot 100=4,18 \%
\end{gathered}
$$

- if the „territorial profile” drawn by the values of the $\omega$ variable, namely the worldwide number of plug-in hybrid electric vehicles in use, „twinkles” through the $\omega_{t_{i}}=a+b \cdot t_{i}+c t_{i}^{2}$ „mould”, $a$ and $b$ will be [4]:

Table 7. The „recipe of the texture" for the grouping of the values regarding the $\omega$ variable, namely the worldwide number of plug-in hybrid electric vehicles in use, if the „profile” has as hypothesis a quadratic tendency

\begin{tabular}{|c|c|c|c|c|c|c|c|}
\hline & $\begin{array}{c}\text { THE } \\
\text { WORLDWIDE } \\
\text { NUMBER OF } \\
\text { PLUG-IN HYBRID } \\
\text { ELECTRIC } \\
\text { VEHICLES IN USE } \\
\text { (MILIONS } \\
\text { UNITS) }\left(\omega_{i}\right)\end{array}$ & \multicolumn{7}{|c|}{\begin{tabular}{l} 
PARABOLIC TENDENCY \\
\cline { 3 - 9 }
\end{tabular}} & $t_{i}$ & $t_{i}^{2}$ & $t_{i}^{4}$ & $t_{i}^{2} \omega_{i}$ & $\omega_{t_{i}}=a+b t_{i}+c t_{i}^{2}$ & $\left|\omega_{i}-\omega_{t_{i}}\right|$ \\
\hline $\mathbf{2 0 1 6}$ & $\mathbf{0 , 8 1}$ & -1 & 1 & 1 & 0,81 & 0,81 & 0 \\
\hline $\mathbf{2 0 1 7}$ & $\mathbf{1 , 2 0}$ & 0 & 0 & 0 & 0 & 1,20 & 0 \\
\hline $\mathbf{2 0 1 8}$ & $\mathbf{1 , 8 2}$ & +1 & 1 & 1 & 1,82 & 1,82 & 0 \\
\hline TOTAL & $\mathbf{3 , 8 3}$ & & 2 & 2 & 2,63 & 3,83 & 0 \\
\hline
\end{tabular}

$$
a=\frac{2 \cdot 3,83-2 \cdot 2,63}{3 \cdot 2-2^{2}}=1,2 \quad b=\frac{3 \cdot 1,01}{3 \cdot 2}=0,505
$$




$$
\begin{gathered}
c=\frac{3 \cdot 2,63-2 \cdot 3,83}{3 \cdot 2-2^{2}}=0,115 \\
V_{I I}=\left[\frac{\sum_{i=-m}^{m}\left|\omega_{i}-\omega_{t_{i}}^{I I}\right|}{n}: \frac{\sum_{i=-m}^{m} \omega_{i}}{n}\right] \cdot 100=\frac{\sum_{i=-m}^{m}\left|\omega_{i}-\omega_{t_{i}}^{I I}\right|}{\sum_{i=-m}^{m} \omega_{i}} \cdot 100=\frac{0}{3,83} \cdot 100=0 \%
\end{gathered}
$$

- if the "territorial profile" drawn by the values of the $\omega$ variable, namely the worldwide number of plug-in hybrid electric vehicles in use, "twinkles” through the $\omega_{t_{i}}=a b^{t_{i}}$ „mould”, $a$ and $b$ will be [4]:

Table 8. The „recipe of the mix” for the grouping of the values regading the $\omega$ variable, namely

\begin{tabular}{|c|c|c|c|c|c|c|}
\hline \multirow{2}{*}{ YEARS } & \multirow{2}{*}{$\begin{array}{l}\text { THE WORLDWIDE } \\
\text { NUMBER OF } \\
\text { PLUG-IN HYBRID } \\
\text { ELECTRIC } \\
\text { VEHICLES IN USE } \\
\text { (MILLIONS } \\
\text { UNITS) }\left(\omega_{i}\right)\end{array}$} & \multicolumn{5}{|c|}{ EXPONENTIAL TENDENCY } \\
\hline & & $\lg \omega_{i}$ & $t_{i} \lg \omega_{i}$ & $\lg \omega_{t_{i}}=\lg a+t_{i} \lg b$ & $\omega_{t_{i}}=a b^{t_{i}}$ & $\omega_{i}-\omega_{t_{i}}$ \\
\hline 2016 & $\mathbf{0 , 8 1}$ & $-0,091514981$ & 0,091514981 & $-0,093213967$ & 0,806837421 & 0,003 \\
\hline 2017 & 1,20 & 0,079181246 & 0 & 0,082579217 & 1,209425767 & 0,009 \\
\hline 2018 & 1,82 & 0,260071388 & 0,260071388 & 0,258372398 & 1,812893943 & 0,007 \\
\hline TOTAL & 3,83 & 0,247737653 & 0,351586369 & & & 0,019 \\
\hline
\end{tabular}
the worldwide number of plug-in hybrid electric vehicles in use, if the „profile” has as hypothesis

$\lg a=\frac{0,247737653 \cdot 2}{3 \cdot 2}=0,082579217 \quad \lg b=\frac{3 \cdot 0,351586369}{3 \cdot 2}=0,175793184$

$$
\begin{gathered}
v_{\exp }=\left[\frac{\sum_{i=-m}^{m}\left|\omega_{i}-\omega_{t_{i}}^{\exp }\right|}{n}: \frac{\sum_{i=-m}^{m} \omega_{i}}{n}\right] \cdot 100=\frac{\sum_{i=-m}^{m}\left|\omega_{i}-\omega_{t_{i}}^{\exp }\right|}{\sum_{i=-m}^{m} \omega_{i}} \cdot 100=\frac{0,019}{3,83} \cdot 100=0,50 \% \\
v_{I I}=0 \%<v_{\exp }=0,50 \%<v_{I}=4,18 \%
\end{gathered}
$$

The look concerning the progress for $\omega$ factor, which records the worldwide number of plug-in hybrid electric vehicles in use, is a $\omega_{t_{i}}=a+b \cdot t_{i}+c t_{i}^{2}$ quadratic contour.

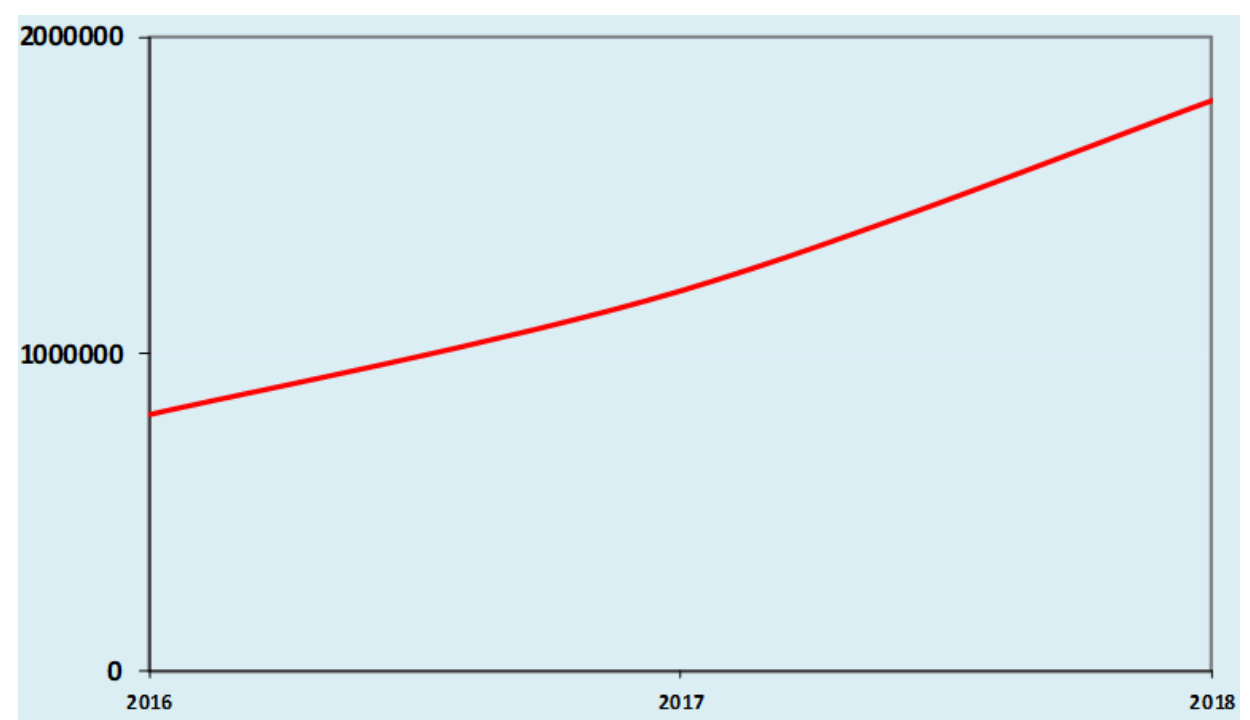

Graph 2. The quadratic countenance regarding the worldwide values of plug-in hybrid electric vehicles in use

\footnotetext{
$\omega_{2020}^{\text {WORDLWIDE_PLUG-IN _HYBRID_ELECTRIC_VEHICLES_IN_USE }}=1,2+0,505 \cdot 3+0,115 \cdot 3^{2}=3,75_{-}$_millions_units

$\omega_{2021}^{\text {WORLDWIDE_PLUG-IN_HYBRID_ELECTRIC_VEHICLES_IN_USE }}=1,2+0,505 \cdot 4+0,115 \cdot 4^{2}=5,06_{-}$millions_units
} 
4. The previsions unveiled through the structure of the model concerning the values which have as target the worldwide sales of plug-in hybrid electric vehicles

Table 9 The values concerning the number of plug-in hybrid electric vehicles worldwide sales

\begin{tabular}{|c|c|}
\hline YEARS & $\begin{array}{c}\text { THE NUMBER OF PLUG-IN HYBRID ELECTRIC VEHICLES } \\
\text { WORLDWIDE SALES } \\
(\mathbf{1 0 0 0} \text { units })\end{array}$ \\
\hline 2012 & $\mathbf{6 0 , 4 8}$ \\
\hline 2013 & $\mathbf{9 1 , 8 2}$ \\
\hline 2014 & $\mathbf{1 3 4 , 8 0}$ \\
\hline 2015 & $\mathbf{2 2 2 , 7 8}$ \\
\hline 2016 & $\mathbf{2 8 8 , 4 9}$ \\
\hline 2017 & $\mathbf{4 2 0 , 1 2}$ \\
\hline 2018 & $\mathbf{6 3 0 , 1 6}$ \\
\hline & The sourse: „Statistics Portal United States" \\
\hline
\end{tabular}

- if the „territorial profile” drawn by the values of the ${ }^{\circ}$ variable, namely the number of plug-in hybrid electric vehicles worldwide sales, „twinkles” through the $\wp_{t_{i}}=a+b \cdot t_{i}$ „mould”, a and b will be [4]:

Table 10 The „recipe of the composition” for the grouping of the values concerning the $\wp$ variable, namely the number of plug-in hybrid electric vehicles worldwide sales, if the „profile” has as hypothesis a linear tendency

\begin{tabular}{|c|c|c|c|c|c|c|}
\hline \multirow{2}{*}{ YEARS } & \multirow{2}{*}{$\begin{array}{c}\text { THE NUMBER OF } \\
\text { PLUG-IN HYBRID } \\
\text { ELECTRIC VEHICLES } \\
\text { WORLDWIDE SALES } \\
\left(10^{3}\right) \\
\left(\wp_{i}\right)\end{array}$} & \multicolumn{5}{|c|}{ LINEAR TENDENCY } \\
\hline & & $t_{i}$ & $t_{i}^{2}$ & $t_{i} \wp_{i}$ & $\wp_{t_{i}}=a+b t_{i}$ & $\mid \wp_{i}-\wp_{t_{i}}$ \\
\hline 2012 & 60,48 & -3 & 9 & $-181,44$ & $-47,04821429$ & 107,53 \\
\hline 2013 & 91,82 & -2 & 4 & $-183,64$ & 42,92785714 & 48,89 \\
\hline 2014 & 134,80 & -1 & 1 & $-134,80$ & 132,9039286 & 1,90 \\
\hline 2015 & 222,78 & 0 & 0 & 0 & 222,88 & 0,10 \\
\hline 2016 & 288,49 & +1 & 1 & 288,49 & 312,8560714 & 24,37 \\
\hline 2017 & 420,12 & +2 & 4 & 840,24 & 402,8321429 & 17,31 \\
\hline 2018 & 630,16 & +3 & 9 & 1890,48 & 492,8082143 & 137,35 \\
\hline TOTAL & 1560,16 & 0 & 28 & 2519,33 & 1560,16 & 337,45 \\
\hline & $\begin{array}{c}a=\frac{1560,}{7} \\
v_{I}=\frac{\sum_{i=-m}^{m} \mid \wp_{i}-\wp}{n}\end{array}$ & $\begin{array}{l}\frac{28}{\sum_{i=-m}^{m} \wp_{i}} \\
n\end{array}$ & $\begin{array}{r}22,8 \\
\cdot 100\end{array}$ & $\begin{array}{l}\frac{7 \cdot 251}{7 \cdot 2} \\
-\wp_{t_{i}}^{I} \mid \\
\wp_{i}\end{array}$ & $\frac{337,45}{1560,16} \cdot 100=$ & $3 \%$ \\
\hline
\end{tabular}

- if the „territorial profile” drawn by the values of the $\bigodot$ variable, namely the number of plug-in hybrid electric vehicles worldwide sales, ,twinkles” through the $\wp_{t_{i}}=a+b \cdot t_{i}+c t_{i}^{2}$ „mould”, a and b will be [4]:

Table 11. The „recipe of the texture” for the grouping of the values concerning the $\wp$ variable, namely the number of plug-in hybrid electric vehicles worldwide sales, if the „profile” has as hypothesis a quadratic tendency

\begin{tabular}{|c|c|c|c|c|c|c|c|}
\hline & $\begin{array}{c}\text { THE NUMBER OF } \\
\text { PLUG-IN HYBRID } \\
\text { YEARS }\end{array}$ & \multicolumn{7}{|c|}{$\begin{array}{c}\text { PLECTRIC VEHICLES } \\
\text { WORLDWIDE SALES }\end{array}$} & $t_{i}$ & $t_{i}^{2}$ & $t_{i}^{4}$ & $t_{i}^{2} \wp_{i}$ & $\wp_{t_{i}}=a+b t_{i}+c t_{i}^{2}$ & $\left|\wp_{i}-\wp_{t_{i}}\right|$ \\
\cline { 5 - 9 } & $\begin{array}{c}\left(\wp^{3}\right) \\
\left(\wp_{i}\right)\end{array}$ & & & & & & \\
\hline $\mathbf{2 0 1 2}$ & $\mathbf{6 0 , 4 8}$ & -3 & 9 & 81 & 544,32 & 98,55714287 & 38,08 \\
\hline $\mathbf{2 0 1 3}$ & $\mathbf{9 1 , 8 2}$ & -2 & 4 & 16 & 367,28 & 42,92785716 & 48,89 \\
\hline $\mathbf{2 0 1 4}$ & $\mathbf{1 3 4 , 8 0}$ & -1 & 1 & 1 & 134,80 & 45,54071430 & 89,26 \\
\hline $\mathbf{2 0 1 5}$ & $\mathbf{2 2 2 , 7 8}$ & 0 & 0 & 0 & 0 & 106,3957143 & 116,38 \\
\hline $\mathbf{2 0 1 6}$ & $\mathbf{2 8 8 , 4 9}$ & +1 & 1 & 1 & 288,49 & 225,4928572 & 63,00 \\
\hline $\mathbf{2 0 1 7}$ & $\mathbf{4 2 0 , 1 2}$ & +2 & 4 & 16 & 1680,48 & 402,8321429 & 17,29 \\
\hline $\mathbf{2 0 1 8}$ & $\mathbf{6 3 0 , 1 6}$ & +3 & 9 & 81 & 5671,44 & 638,4135715 & 8,25 \\
\hline TOTAL & $\mathbf{1 5 6 0 , 1 6}$ & 0 & 28 & 196 & 8686,81 & 1560,16 & 381,15 \\
\hline
\end{tabular}




$$
\begin{gathered}
a=\frac{196 \cdot 1560,16-28 \cdot 8686,81}{7 \cdot 196-28^{2}}=106,3957143 \quad b=\frac{7 \cdot 2519,33}{7 \cdot 28}=89,97607143 \\
c=\frac{7 \cdot 8686,81-28 \cdot 1560,16}{6 \cdot 196-28^{2}}=29,12107143 \\
v_{I I}=\left[\frac{\sum_{i=-m}^{m}\left|\wp_{i}-\wp_{t_{i}}^{I I}\right|}{n}: \frac{\sum_{i=-m}^{m} \wp_{i}}{n}\right] \cdot 100=\frac{\sum_{i=-m}^{m}\left|\wp_{i}-\wp_{t_{i}}^{I I}\right|}{\sum_{i=-m}^{m} \wp_{i}} \cdot 100=\frac{381,15}{1560,16} \cdot 100=24,43 \%
\end{gathered}
$$

- if the „territorial profile” drawn by the values of the $\wp$ variable, namely the number of plug-in hybrid electric vehicles worldwide sales, „twinkles” through the $\wp_{t_{i}}=a b^{t_{i}}$ „mould”, a and b will be [4]:

\begin{tabular}{|c|c|c|c|c|c|c|}
\hline \multirow[b]{3}{*}{ YEARS } & & & ponential & & & \\
\hline & \multirow{2}{*}{$\begin{array}{c}\text { THE NUMBER OF } \\
\text { PLUG-IN HYBRID } \\
\text { ELECTRIC VEHICLES } \\
\text { WORLDWIDE SALES } \\
\left(10^{3}\right)\left(\wp_{i}\right)\end{array}$} & \multicolumn{5}{|c|}{ EXPONENTIAL TENDENCY } \\
\hline & & $\lg \wp_{i}$ & $t_{i} \lg \wp_{i}$ & $\lg \wp_{t_{i}}=\lg a+t_{i} \lg b$ & $\wp_{t_{i}}=a b^{t_{i}}$ & $\left|\wp_{i}-\wp_{t_{t}}\right|$ \\
\hline 2012 & 60,48 & 1,781611782 & $-5,344835347$ & 1,796635379 & 62,60879987 & 2.13 \\
\hline 2013 & 91,82 & 1,962937288 & $-3,925874577$ & 1,964665020 & 92,18601038 & 0,37 \\
\hline 2014 & 134,80 & 2,129689892 & $-2,129689892$ & 2,132694661 & 135,7358794 & 0,94 \\
\hline 2015 & 222,78 & 2,347876200 & 0 & 2,300724302 & 199,8592724 & 22,92 \\
\hline 2016 & 288,49 & 2,460130764 & 2,460130764 & 2,468753943 & 294,2753894 & 5,79 \\
\hline 2017 & 420,12 & 2,623373357 & 5,246746714 & 2,636783584 & 433,2949067 & 13,17 \\
\hline 2018 & 630,16 & 2,799450832 & 8,398352497 & 2,804813225 & 637,9890502 & 7,83 \\
\hline TOTAL & 1560,16 & 16,10507012 & 4,704829966 & & & 53,15 \\
\hline
\end{tabular}

Table 12. The „recipe of the mix" for the grouping of the values concerning the $\wp^{\text {variable, namely }}$ the number of plug-in hybrid electric vehicles worldwide sales, if the „profile” has as hypothesis

$$
\begin{gathered}
\lg a=\frac{16,10507012 \cdot 28}{7 \cdot 28}=2,300724302 \lg b=\frac{7 \cdot 4,704829966}{7 \cdot 28}=0,168029641 \\
v_{\text {exp }}=\left[\frac{\sum_{i=-m}^{m}\left|\wp_{i}-\wp_{t_{i}}^{\exp }\right|}{n}: \frac{\sum_{i=-m}^{m} \wp_{i}}{n}\right] \cdot 100=\frac{\sum_{i=-m}^{m}\left|\wp_{i}-\wp_{t_{i}}^{\exp }\right|}{\sum_{i=-m}^{m} \wp_{i}} \cdot 100=\frac{53,15}{1560,16} \cdot 100=3,41 \% \\
v_{\text {exp }}=3,41 \%<v_{I}=21,63 \%<v_{\text {exp }}=24,43 \%
\end{gathered}
$$

The look regarding the progress reflected by $\wp$ variable, namely the number of plug-in hybrid electric vehicles worldwide sales, is moulded by the $\wp_{t_{i}}=a b^{t_{i}}$ exponential contour.

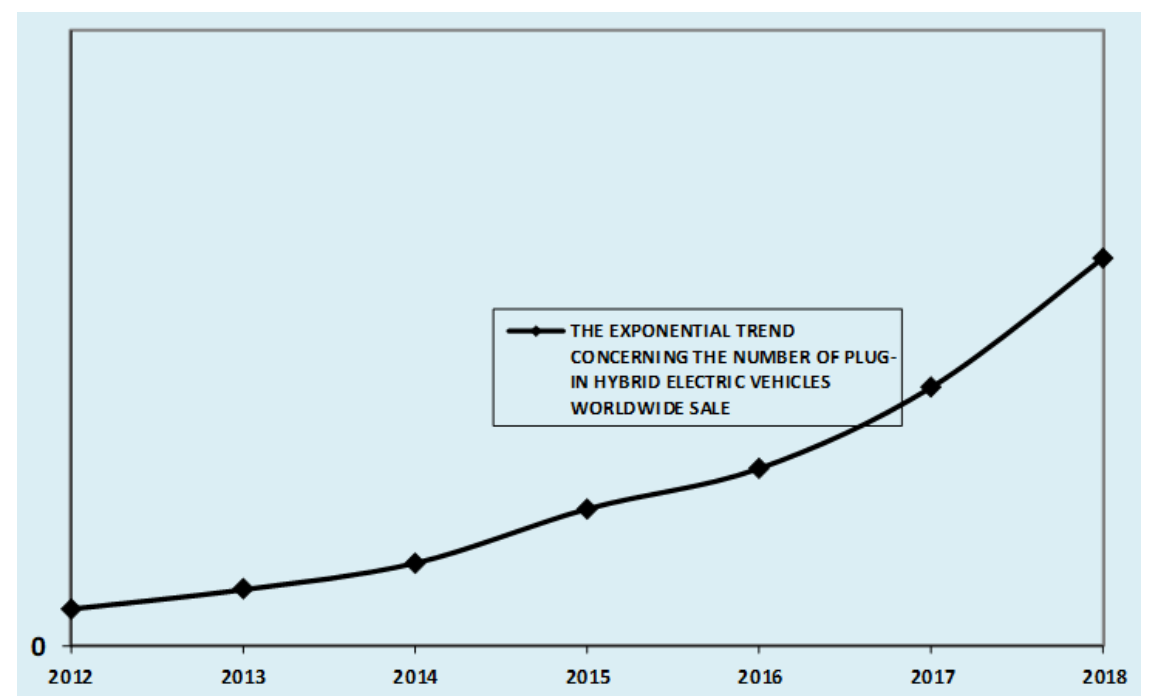

Graph 3. The exponential countenance concerning the values of the worldwide sales of plug-in hybrid electric vehicles 
$\wp_{2020}^{\text {WORLDWIDE_PLUG-IN_ELECTRIC_VEHICLES_SALES }}=199,8592724 \cdot 1,472412993^{5}=1383,16$ _thousands_units

$\wp_{2021}^{\text {WORLDWIDE_PLUG-IN_ELECTRIC_VEHICLES_SALES }}=199,8592724 \cdot 1,472412993^{6}=2036,58$ _thousands_units

5. The predictions exposed through the texture of the model regarding the values which focuse the worldwide sales of plug-in light vehicles

Table 13. The values regarding the number of plug-in light vehicles worldwide sales, between 2015 2019

\begin{tabular}{|c|c|}
\hline YEARS & $\begin{array}{c}\text { THE NUMBER OF PLUG-IN LIGHT VEHICLES WORLDWIDE SALES } \\
\text { (million units) }\end{array}$ \\
\hline 2015 & $\mathbf{0 , 5 5}$ \\
\hline 2016 & $\mathbf{0 , 8 0}$ \\
\hline 2017 & $\mathbf{1 , 2 8}$ \\
\hline 2018 & $\mathbf{2 , 0 2}$ \\
\hline 2019 & $\mathbf{2 , 2 1}$ \\
\hline
\end{tabular}

The sourse: „Statistics Portal United States”

- if the „territorial profile” drawn by the values of the $\gamma$ variable, namely the number of plug-in light vehicles worldwide sales, „twinkles” through the $\gamma_{t_{i}}=a+b \cdot t_{i}$ „mould”, $a$ and $b$ will be [4]:

Table 14. The „recipe of the composition” for the grouping of the values concerning the $\gamma$ variable, namely the number of plug-in light vehicles worldwide sales, if the „profile” has as hypothesis

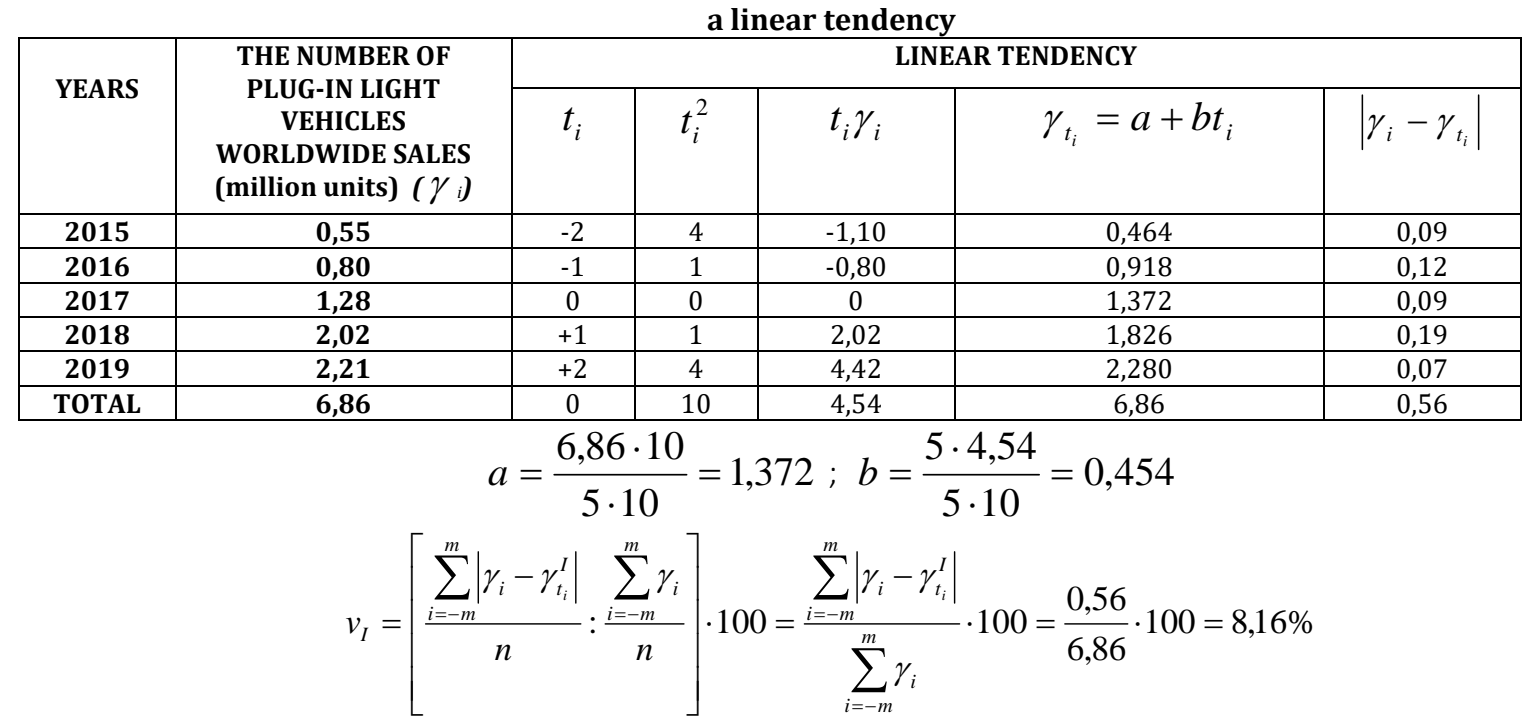

- if the "territorial profile" drawn by the values of the $\gamma$ variable, namely the number of plug-in light vehicles worldwide sales, „twinkles” through the $\gamma_{t_{i}}=a+b \cdot t_{i}+c t_{i}^{2}$,mould”, $a$ and $b$ will be [4]:

Table 15. The „recipe of the texture” for the grouping of the values concerning the $\gamma$ variable, namely the number of plug-in light vehicles worldwide sales, if the „profile” has as hypothesis a quadratic tendency

\begin{tabular}{|c|c|c|c|c|c|c|c|}
\hline \multirow{2}{*}{ YEARS } & \multirow{2}{*}{$\begin{array}{l}\text { THE NUMBER OF PLUG- } \\
\text { IN LIGHT VEHICLES } \\
\text { WORLDWIDE SALES } \\
\text { (million units) }\left(\gamma_{i}\right)\end{array}$} & \multicolumn{6}{|c|}{ PARABOLIC TENDENCY } \\
\hline & & $t_{i}$ & $t_{i}^{2}$ & $t_{i}^{4}$ & $t_{i}^{2} \gamma_{i}$ & $\gamma_{t_{i}}=a+b t_{i}+c t_{i}^{2}$ & $\mid \gamma_{i}-\gamma_{t_{i}}$ \\
\hline 2015 & 0,55 & -2 & 4 & 16 & 2,20 & 0,484 & 0,07 \\
\hline 2016 & $\mathbf{0 , 8 0}$ & -1 & 1 & 1 & 0,80 & 0,908 & 0,11 \\
\hline 2017 & 1,28 & 0 & 0 & 0 & 0 & 1,352 & 0,07 \\
\hline 2019 & 2,21 & +2 & 4 & 16 & 8,84 & 2,300 & 0,09 \\
\hline TOTAL & 6,86 & 0 & 10 & 34 & 13,86 & 6,86 & 0,54 \\
\hline
\end{tabular}

$$
a=\frac{34 \cdot 6,86-10 \cdot 13,86}{5 \cdot 34-10^{2}}=1,352 \quad b=\frac{5 \cdot 4,54}{5 \cdot 10}=0,454 \quad c=\frac{5 \cdot 13,86-10 \cdot 6,86}{5 \cdot 34-10^{2}}=0,01
$$




$$
v_{I I}=\left[\frac{\sum_{i=-m}^{m}\left|\gamma_{i}-\gamma_{t_{i}}^{I I}\right|}{n}: \frac{\sum_{i=-m}^{m} \gamma_{i}}{n}\right] \cdot 100=\frac{\sum_{i=-m}^{m}\left|\gamma_{i}-\gamma_{t_{i}}^{I I}\right|}{\sum_{i=-m}^{m} \gamma_{i}} \cdot 100=\frac{0,54}{6,86} \cdot 100=7,87 \%
$$

- if the "territorial profile" drawn by the values of the $\gamma$ variable, namely the number of plug-in light vehicles worldwide sales, „twinkles” through the $\gamma_{t_{i}}=a b^{t_{i}}$ „mould”, $a$ and $b$ will be [4]:

Table 16 The "recipe of the mix" for the grouping of the values concerning the $\gamma$ variable, namely the number of plug-in light vehicles worldwide sales, if the „profile” has as hypothesis

\begin{tabular}{|c|c|c|c|c|c|c|}
\hline \multirow{2}{*}{ YEARS } & \multirow{2}{*}{$\begin{array}{c}\text { THE NUMBER OF } \\
\text { PLUG-IN LIGHT } \\
\text { VEHICLES } \\
\text { WORLDWIDE SALES } \\
\left(10^{\circ}\right)\left(\gamma_{i}\right)\end{array}$} & \multicolumn{5}{|c|}{ EXPONENTIAL TENDENCY } \\
\hline & & $\lg \gamma_{i}$ & $t_{i} \lg \gamma_{i}$ & $\lg \gamma_{t_{i}}=\lg a+t_{i} \lg b$ & $\gamma_{t_{i}}=a b^{t_{i}}$ & $\gamma_{i}-\gamma_{t_{i}}$ \\
\hline 2015 & 0,55 & $-0,259637310$ & 0,519274621 & $-0,241982853$ & 0,572818646 & 0,02 \\
\hline 2016 & $\mathbf{0 , 8 0}$ & $-0,096910013$ & 0,096910013 & $-0,080950798$ & 0,829944788 & 0,03 \\
\hline 2017 & 1,28 & 0,107209969 & 0 & 0,080081257 & 1,202489401 & 0,08 \\
\hline 2018 & 2,02 & 0,305351369 & 0,305351369 & 0,241113312 & 1,742261388 & 0,28 \\
\hline 2019 & 2,21 & 0,344392273 & 0,688784547 & 0,402145367 & 2,524325573 & 0,31 \\
\hline TOTAL & 6,86 & 0,400406288 & 1,610320550 & & & 0,72 \\
\hline
\end{tabular}

$$
\begin{gathered}
\lg a=\frac{0,400406288 \cdot 10}{5 \cdot 10}=0,080081257 \quad \lg b=\frac{5 \cdot 1,61032055}{5 \cdot 10}=0,161032055 \\
v_{\exp }=\left[\frac{\sum_{i=-m}^{m}\left|\gamma_{i}-\gamma_{t_{i}}^{\exp }\right|}{n}: \frac{\sum_{i=-m}^{m} \gamma_{i}}{n}\right] \cdot 100=\frac{\sum_{i=-m}^{m}\left|\gamma_{i}-\gamma_{t_{i}}^{\exp }\right|}{\sum_{i=-m}^{m} \gamma_{i}} \cdot 100=\frac{0,72}{6,86} \cdot 100=10,50 \% \\
v_{I I}=7,87 \%<v_{I}=8,16 \%<v_{\exp }=10,50 \%
\end{gathered}
$$

The look concerning the progress for $\gamma$ factor, which records the number of plug-in light vehicles worldwide sales, is a $\gamma_{t_{i}}=a+b \cdot t_{i}+c t_{i}^{2}$ quadratic contour.

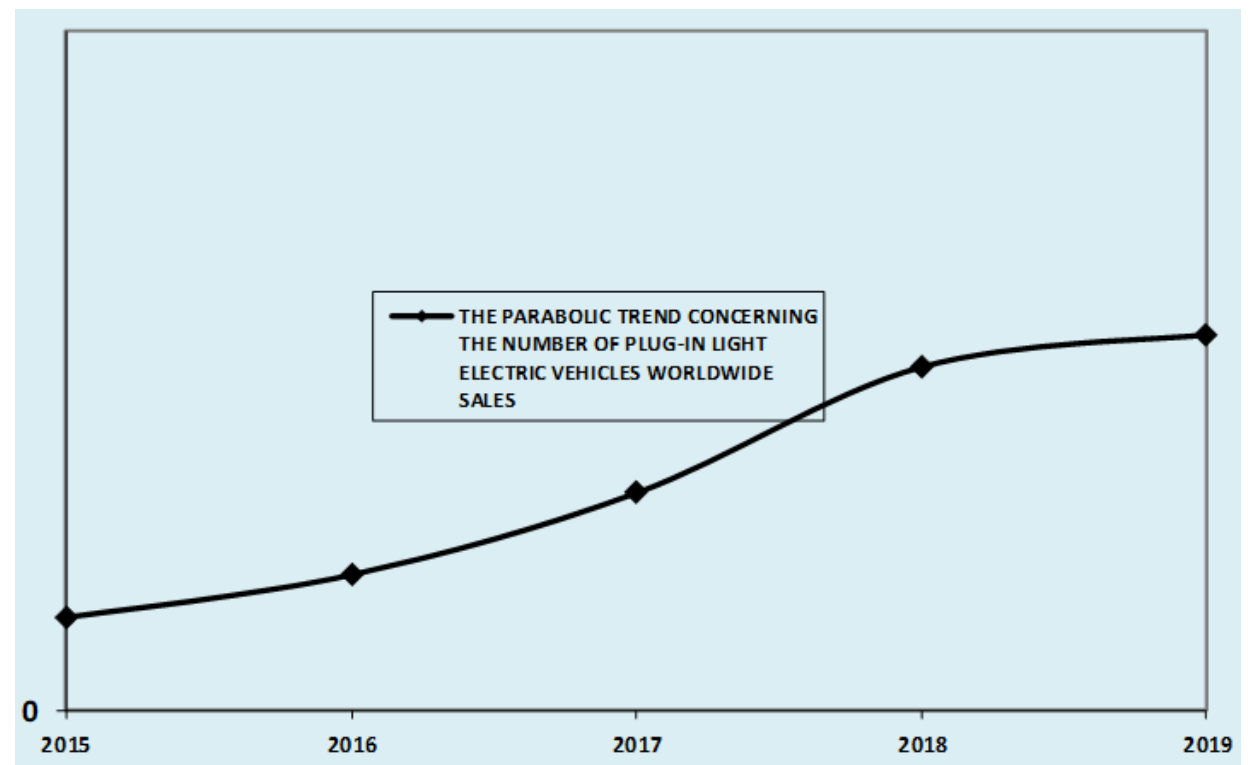

Graph 4. The quadratic countenance for the values of the worldwide sales of plug-in light vehicles

$$
\begin{aligned}
& \gamma_{2020}^{\text {WORLDWIDE_PLUG-IN_LIGHT_VEHICLES_SALES }}=1,352+0,454 \cdot 3+0,01 \cdot 3^{2}=2,80 \text { _millions_units } \\
& \gamma_{2021}^{\text {WORLDWIDE_PLUG-IN_LIGHT_VEHICLES_SALES }}=1,352+0,454 \cdot 4+0,01 \cdot 4^{2}=3,33 \text { _millions_units }
\end{aligned}
$$

\section{Conclusions}

We can see that in 2020, respectively in 2021, the worldwide values of the battery electric vehicles in use rise at 10754,75 thousands units, respectively 18743,88 thousands units, which it means in relative 
sizes an increase with $226,81 \%$ in 2020 comparative to 2018, respectively with $469,58 \%$ in 2021 comparative with 2018. As well, we can observe that in 2020, respectively in 2021, the worldwide values of the plug-in hybrid electric vehicles in use grow up at 3,75 millions units, respectively at 5,06 millions units and in dynamics, these values highlight a rise with $106,04 \%$ in 2020 reported at 2018, respectively with $178,02 \%$ in 2021 comparable with 2018. Likewise, we can evaluate that in 2020, respectively in 2021, the values of the worldwide sales of plug-in hybrid electric vehicles swell at 1383,15 thousands units in 2020, respectively 2036,58 thousands units in 2021 and in relative sizes, these increases signify a rise with 119,49 $\%$ in 2020 compared to 2018 , respectively with $223,18 \%$ in 2021 compared with 2018 . Also, we can treasure that in 2020, respectively in 2021, the worldwide values of the plug-in light vehicles in use jump at 2,80 millions units in 2020, respectively at 3,33 millions units in 2021, values which display rises in relative sizes with $26,70 \%$ in 2020 comparable with 2019, respectively with 50,68 \% in 2021 „face to face” with 2019.

\section{References}

[1] Allen J. - „Thinking Critically Electric Cars”, ReferencePoint Press Incorporated Publishing House, San Diego,2019.

[2] Chitra A., Padmanaban S., Holm-Nielsen J.B., Himavathi S. - „Artificial Intelligence Techniques for Electric and Hybrid Electric Vehicles”, John Wiley \& Sons Publishing House, New Jersey, 2020.

[3] Contestabile M., Tail G., Turrentine T. - „Who's Driving Electric Cars - Understanding Consumer Adoption and Use of Plug-In Electric Cars", Springer Publishing House, New York, 2020.

[4] Gauss C.F. - „Disquisitiones Arithmeticae And Other Papers On Number Theory”, english translation Springer Publishing House, New York, 1986. 